\title{
Scalar representations in the semantics of Japanese. From measurements to pragmatics -The case of dokoroka-
}

\author{
Szymon Grzelak \\ ADAM MICKIEWICZ UNIVERSITY IN POZNAŃ \\ sgrzelak@amu.edu.pl
}

\begin{abstract}
This study looks into the scalar properties exhibited by some grammaticalized (and subsequently pragmaticalized) expressions of Japanese that are lexically based on the noun tokoro 'place'. In particular, the argument will be focused on a conjunctive particle $p$ dokoroka $q$ 'q, let alone p'. In most cases, both $p$ and $q$ can be ascribed some pragmatically inferred scalar values reflecting gradable properties, but the assessment of such a common scale is difficult in some cases. We argue that such "non-scalar" instances of dokoro-ka, occurring in enumerations, can be represented as cardinalities in the semantic model.
\end{abstract}

\section{Introduction 1}

In this study we analyze a lexically place-based item tokoro, focusing on one particular instance, i.e. $p$ dokoroka $q$, which is usually translated as 'q, let alone p'. The analysis is carried out from the viewpoint of its scalarity, i.e. the possibility of semantic analysis by means of ordered sets of values representing intensity of lexical properties.

The paper is organized as follows. Section one introduces some theoretical notions that are of importance to the analysis presented in the subsequent part, in particular, we outline a process of semantic change that results in the conjunctive particle dokoroka. Section two briefly summarizes selected studies devoted to various properties of dokoroka. Finally, in the last section, we examine some instances of the aforesaid conjunctive particle with respect to their scalar properties.

\footnotetext{
${ }^{1}$ I am grateful to the audience gathered at the International Conference on Asian Linguistics held in Ho Chi Minh City for fruitful discussion. I am also very indebt to Kazuya Inagaki, Joachim Kolb and Syuntaroo Tida for several insightful remarks. All remaining errors and inconsistencies are solely mine.
} 


\subsection{Meaning shift}

In an earlier study (Grzelak 2014), we argued for the existence of a threestaged process of meaning shift observed in lexical items, which have a degree component in their semantic structure ${ }^{2}$. In course of the change, grammaticalization is followed by pragmaticalization and subjectification, in the sense of Traugott (2010) and the related line of research. The meaning shift can be exemplified as follows:

$\begin{array}{ll}\text { Stage 1 } & \begin{array}{l}\text { takai kurai-ni tuku } \\ \text { high rank-DAT assume }\end{array} \\ \text { 'To assume a high rank.' } \\ \text { Stage 2 } & \begin{array}{l}\text { motenai kurai omoi } \rightarrow \\ \text { cannot.carry degree heavy }\end{array} \\ \text { '[it is] so heavy that I cannot carry it' } \\ \text { Stage 3 } & \begin{array}{l}\text { otya kurai zibun-de irenasai } \\ \text { tea degree by.yourself make-IMP } \\ \text { 'Make at least [your own] tea by yourself!' }\end{array}\end{array}$

In the first stage, kurai is a "full-fledged" noun, capable of playing the role of a syntactic head, as in the above example. In the second stage, kurai (freely varying with its voiced variant gurai in the two latter stages) plays the role of a degree adverbial, deprived of the lexical meaning present in the preceding stage. Finally, in the third stage, it begins to bear a pragmatic input, such as stance marking, as can be seen in the third example above, uttered with certain impatience. What is worth noting, the degree-based particles can be given scalar semantic representations on each stage of their development, due to their lexical motivation.

In the case of tokoro, the above stages could be illustrated as follows:

$\begin{array}{ll}\text { Stage } 1 & \text { (kaban-o oi-ta) tokoro (spatial noun) } \rightarrow \\ & \rightarrow \\ & \text { 'bag-ACC put-PAST) place } \\ \text { 'The place I put my bag.' }\end{array}$

Stage 2 okonat-teiru tokoro (temporal) $\rightarrow$ carry.out-PROG tokoro '(something is) being carried out'
Stage 3 bentu dokoroka zitensyasae kaenai (pragmatic) Mercedes dokoroka bicycle even buy.cannot 'I cannot even afford a bicycle, let alone a Mercedes Benz.'

\footnotetext{
${ }^{2}$ In the current stage of the inquiry we do not possess sufficient diachronic evidence that could corroborate claims about the historical development of the above stages. The present study is synchronic in nature, based on various forms coexisting in contemporary Japanese.
} 
Tokoro in the first stage is a noun referring to a location in space, capable of taking modification by attributive sentences. Its grammaticalized form in the second stage is an expletive noun denoting a point (or range) in time without any reference to the physical space. Finally, as a part of the complex expression dokoroka, tokoro contributes to marking speaker's attitude, such as frustrated expectation or emphasis of a large difference between $p$ and $q$.

\section{Previous research on dokoroka}

In one of the initial accounts (apart from earlier lexicographical descriptions), Chu (1980) provides the following characteristics of dokoroka with three possible patterns: (i) in the combination of $\mathrm{P}$ and $\mathrm{Q}$ that are mutually exclusive and contrary to each other, $\mathrm{P}$ is negated and $\mathrm{Q}$ is emphasized, (ii) $\mathrm{P}$ and $\mathrm{Q}$ are of different degrees, the degree of $\mathrm{P}$ is negated and the higher degree of $\mathrm{Q}$ is emphasized, (iii) a high-degree $\mathrm{P}$ is overtly negated (by means of ...dokoroka ...nai) and $\mathrm{Q}$ that is of extremely low degree is emphasized. This analysis was criticized by Hattori (1995) who pointed out that the classification can be confusing, it does not cover several instances and that the formal marking of negation (or absence thereof) is not relevant to the semantic analysis. Also, the antonymy and mutual exclusion of $\mathrm{P}$ and $\mathrm{Q}$, postulated in (i), can actually render some sentences with nongradable properties odd (Kare wa dokusin dokoroka kekkon siteiru. 'He is not just single, he is married'). Moreover, the notion of emphasis used in (i)-(iii) above, cf. also Zhang (1993), is too vague to possess any explanatory power. According to Hattori (ibid.: 42), in the $\mathrm{P}$ dokoroka $\mathrm{Q}^{3}$ construction the appropriateness of $\mathrm{P}$ is denied, and some $\mathrm{Q}$ is inferred that is located outside the pair "P vs. p" ( $\mathrm{p}$ : an affair that commonly comes to mind as negation of $\mathrm{P}$ ). Assuming the direction from $\mathrm{P}$ to $\mathrm{p}$ (in terms of degree ordering), $\mathrm{Q}$ is considered to have a higher degree than $\mathrm{P}$; in the case of $\mathrm{p}$ to $\mathrm{P}$ direction, $\mathrm{Q}$ is considered to be of higher degree than $\mathrm{p}$. In Hattori (2005), the relation between the meaning of $\mathrm{P}$ dokoroka and $\mathrm{P}$ dokorodewanai has been further analyzed.

In the existing studies, dokoroka is classified as a pragmaticalized adverbial or a conjunctive particle. It can be considered an instance of metalinguistic negation (Horn 2001) realized by means of a voiced variant of the expletive noun tokoro and a modal particle $k a$ marking interrogativity or conjecture. The speaker challenges the degree that can be inferred from $p$ and, instead, claims it to be some value $q$, fairly remote from $p$ (Masuoka and Takubo 1992, Hattori 2006). A very important aspect of dokoroka, the notion of expectation, discussed in the following section, was already treated in (Kawabata 2014). According to the author, 'the value of $Q$ is the opposite of the direction of expectation on the scale of the degree of expectation presumed when $\mathrm{p}$ is set' (ibid.).

3 Capital letters were used by Hattori to represent the arguments of dokoroka, whilst small caps marked their inferred negation. 
In another study, Sato (2012) discusses how the prosodic properties of expressions linked with dokoroka affect the syntax of such complex sentences. The author argues that in sentences where the combination of $q$ and dokoroka is accented, dokoroka plays the role of a coordinate conjunction joining IPs; in the cases where accent is not preserved, dokoroka joins zero-level categories.

\section{Scalarity of dokoroka}

In this section we look at some instances of ' $p$ dokoroka $q$ ' in order to examine the scalarity of its arguments. Scalarity of $p$ and $q$ can originate from their semantic structure, in the sense of being primarily or secondarily numerical (Rusiecki 1985) i.e. having some underlying scale graded with units of measurement such as meters, kilograms or points, or the relevant scale needs to be inferred pragmatically.

(1) a. (Rieki-wa) zero dokoroka mainasu desu. (profit-TOP) zero dokoroka negative COP 'The profit is not just zero. It is negative.'

b. Me-o akeru to, nagarebosi wa, kieru dokoroka, Eye-ACC open when falling.star TOP disappear dokoroka masumasu ooki-ku nat-tei-ta. increasingly big-ADV become-PROG-PAST 'When I opened my eyes, the meteor not only had not disappeared. Rather, it had grown bigger and bigger.'

c. Hetana nagusame-no kotoba nante, yakunitatanai dokoroka sloppy consolation-GEN word PART useless dokoroka sarani kizutukete-simau kamosirenai. even.more hurt-PERF maybe. 'Sloppy consolations are not just useless, they can hurt even more.'

[KOTONOHA]

In the above examples various scales representing semantic properties are involved. (1a) is based on a straightforward scale representing the amount of financial resources the value of which can turn negative in case of losses. In (1b), the underlying scale represents size of a shooting star. Finally, in (1c) there is some pragmatically inferred scale indicating the extent of emotional damage. The latter type of scalarity ('secondary scalarity' in Rusiecki's terms) can be found in a variety of semantic domains, such as taste (Backhouse 2005, 103-25):

(2) Umi-no mizu-wa syoppai?
sea-GEN water-TOP salty
'Is sea-water salty?' 
Syoppai dokoroka siokarai.

salty dokoroka salt.pungent

'Far from being (just) salty, it's salt.'

(3) Karee-wa piritto-siteru?

curry-TOP piquant-do-PROG

'Is curry piquant?'

Piritto-si-teru dokoroka karai.

piquant-do-PROG dokoroka hot

'Far from being [just] piquant, it's hot.'

(Backhouse 2005, glossing and transcription by the author)

The above sentences show that siokarai and syoppai can be ascribed a common scale, but as Backhouse observes, they should be interpreted as contrast terms 'denoting the quality of saltiness, but in different intensities' (ibid.: 103).

Pragmatically inferred scale of expectation.

The pragmatic effect of dokoroka is bound to the notion of expectation. It can appear as part of the rhetoric strategy of counter-expectation (Elizabeth C. Traugott 1999). The examples presented so far demonstrate that Q can be unexpected by (i) varying to a big extent from P, (ii) being of opposite direction on the scale (non-monotonicity), or by (iii) being something non-homogeneous with $\mathrm{P}$, as in the following example:

(4) Koohaku dokoroka, ko aku utagassen zyanai-ka. red.and.white dokoroka, old bad song.competition COP.NEG-Q 'Is it Red-vs.-White or maybe rather Old-vs.-Bad? [New Year Eve song competition produced by the NHK public broadcaster].'

(Kawabata 2014: 72)

This sentence, relevant to the argument in the following section, clearly does not have any underlying scale in its semantic structure. The role of dokoroka seems to be tantamount to introducing a base for negation as part of a rhetorical figure.

As far as the notion of expectation is concerned, dokoroka, being pragmatically marked, with the reservations voiced by Haspelmath (2006), triggers an expectation of something unexpected. As a result, predictable Qs, such as simple polar antonyms of $\mathrm{P}$, tend to be unnatural due to their very predictability. This intuition is reflected in other accounts (e.g. being too 'obvious' in Hattori 2005). 

a. \#Nagai dokoroka mizikai.
long dokoroka short
'\# It's not long. Far from that: it's short.'

Interestingly, however, sentences as (6a) can be significantly amended by means of adverbs. For example:

(6)
b. Nagai dokoroka totemo mizikai.
long dokoroka very short
'It's not long. Far from that: it's short.'

A possible explanation would be that the addition of an intensifier in (6b) fulfills the condition mentioned in 1.1 of $p$ and $q$ being far apart from each other.

A similar constraint holds for non-gradable antonyms, which can only default to either end of "two-state" scales:

(7) Iki-teiru dokoroka, sin-deiru.
live-PROG dokoroka die-PROG
'\#He's not alive. Far from that, he's dead.'

One important reservation is that in the semantics of degrees, scales are determined contextually (apart from expressions such as ' $10 \mathrm{~cm}$ ' that are not context-sensitive). That is why in the case of dokoroka what is "fairly remote" depends on the context and is determined for a given class of objects (Kennedy and McNally 2005). For example:

(8) 9 byoo dokoroka 10 byoo sae muri da. 9 second dokoroka 10 second even impossible COP

'Not just 9 seconds, even 10 seconds wouldn't be possible.'

The one-second difference in the above example is marginal or negligible in everyday life (if it referred to the length of a lecture or travel), but can be quite significant in sport or physics.

\section{Scalarity of tokoro}

As far as the scalarity of complex degree expressions containing two or more scalar arguments is concerned, there are two possible configurations: (i) the adverbial or connective itself has scalarity in its semantic structure, for example "a wa b HODO (dewanai)" (same for bakari, gurai, teedo and others), or (ii) they are semantically not related to the notion of scalarity, e.g. 'a is longer THAN b', 'a is AS tall AS b'. In the latter examples, than originates from then, and as derives its etymology from Old English alswa, lit. 'all so'. As will be shown below, the question about the proper assigning of 'a DOKOROKA b' to the above dichotomy poses certain difficulties.

As mentioned in 1.1., adverbials such as hodo or kurai/gurai are inherently scalar due to their lexical motivation, i.e. being related to nouns the 
semantic structure of which is based on the component of 'degree'. In the case of tokoro 'place', the scalarity is not always straightforward. Even though the non-grammaticalized, spatial noun tokoro can refer to places in space that are linearly ordered on some scale, much more often it requires two (or three) scales to determine the coordinates $\mathrm{X}, \mathrm{Y},(\mathrm{Z})$ which imposes cognitive burden and makes it hard to process, similarly to the complex dimensional/quantitative adjectives such as big. One can conjecture that some instances of grammaticalized tokoro can be given scalar representations (e.g. in its temporal function, e.g. tabeteiru tokoro 'just eating (now)') whilst others cannot, as is the case with tokoro-de, a topic-shift expression, or tokoro-ga, an adversative discourse marker. It is worth noting that the temporal tokoro and tokoro-de do not reach the stage of subjectification, playing, respectively, the grammatical (temporal/nominalizer) and discourse organizing roles. Also, the question arises whether the three-stage semantic change of degree-based nouns outlined in 1.1. was facilitated by scalarity. So far, no definite claim can be made about scalarity as a factor facilitating the grammaticalization of tokoro, similarly to metaphor. Tokoro, which is not always scalar, may or may not reach the stage of subjectification.

As far as the possible arguments of dokoroka are concerned, the following expressions (or their negations) are possible: verbs, adjectives (morphological and adjectival nouns), nouns, quoted sentences, anaphoric connectives (e.g. sore referring to the preceding context).

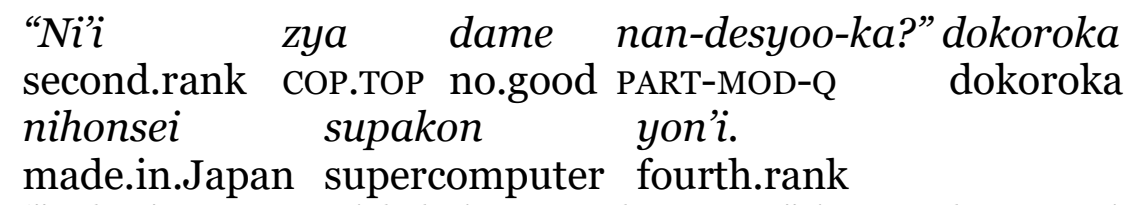

"'What's wrong with being number two?" is not the question. The Japanese supercomputer was fourth in the ranking.'
“Kore-wa keezi dorama ka?” dokoroka
This-TOP detective drama $\mathrm{Q}$ dokoroka
"somosomo, kore-wa dorama nanoka?"
first.of.all this-TOP drama PART-Q
'The question is not just if this is a police drama, but whether it is a drama at all.'

Although the first sentence does contain scalar nouns 'rank' the scale applicable here is in fact 'admissibility of a question'.

On the sentence/paragraph level, scales can be hard to determine unambiguously.

$\begin{array}{lll}\text { (11) Sin-eba, hutatabi } & \text { tenka-ni umare-tekuru } & \text { hosyoo-wa nai. } \\ \text { die-COND again } & \text { world-DAT born-ASP } & \text { guarantee-TOP be.NEG }\end{array}$ 


\begin{abstract}
Sore dokoroka, zigoku-ni massakasama... that dokoroka hell-DAT quite.inversely

toiu koto mo nai-de-wa-nai.

COMPL NMLZ too be.NEG-COP-TOP-NEG

'[...] when we die, there is no guarantee that we will be reborn in this world. What is more, it is not excluded that we might end up in hell.'
\end{abstract}

[KOTONOHA]

The three possibilities that come to mind here would be scales representing the level of guarantee, hell/heaven hierarchy or just negation, but due to the high level of idiosyncrasy, no testing procedure for the type of scale can be established.

\title{
Dokoroka in enumerations
}

Apart from non-scalar instances such as example (4), there is a distinct group of sentences where ascribing a common scale to $p$ and $q$ poses significant difficulty.

(12) Taroo-wa piano dokoroka, otya-mo kyuudoo-mo yat-teiru. Taro-TOP piano dokoroka tea-too archery-too do-PROG 'Taro doesn't just play the piano, he also does tea ceremony and archery.'

There is no obvious common parameter that would allow for scalar ordering among the elements of the above set, i.e. playing piano, practicing tea ceremony and archery4. The scale (a harness of possible scales) can be derived from some factors that are external to the situation described in the sentence. In quantitative terms, in the case of such "enumerative" dokoro$k a$, the number of antecedents (q) must be greater that two. Enumerations with only one additional item are perceived as unnatural.

Taroo-wa piano dokoroka, otya-mo yat-teiru.

Taro-TOP piano dokoroka tea-too do-PROG

\#'Taro doesn't just play the piano, he also does tea ceremony.'

The above sentence is odd, since the required number of items is smaller than three. Alternatively, such enumerations can be treated merely in terms of cardinality where the number of items is greater than two. However, if the anteceding element is unexpected or fairly remote in terms of degree of some lexical property, the sentence can be saved even with two items.

\footnotetext{
4 Another possibility was pointed out to me by Joachim Kolb. It might be conceivable that Taro is not at all into new-fangled Western art forms such as the piano, but heavily into traditional Japanese ones, such as archery and tea. The possible reading in such case would be "Far from going in for gimmicks such as the piano, he actually practices both archery and the tea ceremony."
} 
Taroo-wa piano dokoroka, utyuuhikoosi mo/made yat-teiru. Taro-TOP piano dokoroka astronaut too/as.much.as do-PROG 'Taro doesn't just play the piano, he is also an astronaut.'

In this sentence, the scalar structure is switched to some parameter of the lexical meaning, but its identification is fairly ambiguous.

As can be seen from the following example, dokoroka can take arguments that are overtly cardinality-based, containing e.g. numerals with classifiers.

$$
\begin{aligned}
& \text { Bunkei-no gakusei nitotte wa issya dokoroka } \\
& \text { humanities-GEN student for TOP one.company dokoroka } \\
& \text { zyussya, nizyussya no husaiyoo mo } \\
& \text { ten.companies twenty.companies GEN rejection too } \\
& \text { mezurasiku-nai daroo. } \\
& \text { rare-NEG MOD } \\
& \text { 'For a humanities student, being rejected by not just one company, } \\
& \text { but even ten or twenty is nothing unusual.' }
\end{aligned}
$$

The number of companies can be straightforwardly represented by means of a scale without any pragmatic inference.

\section{Summary}

In the argument presented above, we tried to shed some light on two issues. First, the existence of a semantic change was proposed, in which place-based noun tokoro evolves from a full-fledged lexical item that can play the role of syntactic head towards grammaticalized expletive form that can undergo a subsequent stage of pragmaticalization/subjectification (typically: emphasis, attitude marking, rhetorical, figures of speech, etc.). Second, we focused on a complex conjunction, dokoroka, typically assumed to trigger some scalar inference. There are however some instances of dokoroka in the case of which assigning an appropriate scale can be fairly challenging. We argued that such sentences are in fact enumerations conveying cardinalities of sets of homogeneous objects rather than comparisons of (fairly remote) degrees.

We observed that tokoro is not inherently scalar due to its threedimensional spatial motivation, even though it might be possible to propose a topology ordering places in a space from left to right or according to the distance from some center point. Interestingly, some grammaticalized tokoro can be given scalar representations, as is the case with its temporal grammaticalized form.

In conclusion, some (inter-)subjectified discourse markers in Japanese are the final result of a three-stage meaning shift. All degree-based markers are scalar. Some place-based markers can be scalar. The expressions exhibit various kinds of scalarity - scalar values, scale of expectation, mul- 
tiple scales available in the interpretation process. Unlike $k u$ rai/bakari/hodo, that can play the role of pragmatically neutral degree adverbs, dokoroka inherently contributes some pragmatic input.

The claims presented in this study were based solely on the synchronic evidence. In the course of further research, the history of the meaning shift discussed here needs to be elucidated based on empirical evidence from historical corpora.

\section{References}

Backhouse, A. E. 2005. The Lexical Field of Taste: A Semantic Study of Japanese Taste Terms. Supplement edition. Cambridge: Cambridge University Press.

Chu，Yu Lin. 1980. “どころかーその接続と意味の説明・分類をめぐって (Dokoroka - Explanation and Classification of Connected Expressions and Meanings).” 言語 10-10.

Grzelak, Szymon. 2014. "Pragmaticalization of Hedging Markers in Japanese." Rocznik Orientalistyczny, no. 1.

Haspelmath, Martin. 2006. "Against Markedness (and What to Replace It With)." Journal of Linguistics 42 (1): 25-70.

Hattori Tadasu. 1995. “「〜どころか (どころではない)」等の意味用法について.” 『同志社女子大学日本語日本文学』7, 43--58.

-ー-. 2005. “「〜どころか (どころではない)」再論.” 総合文化研究所紀要 22 (March): 165-74.

Horn, Laurence R. 2001. A Natural History of Negation. 2nd version. Stanford, Calif: Stanford Univ Center for the Study.

Kawabata, Motoko. 2014. “程度表現「P どころか Q」における反期待の構造 (Structure of Anti-Expectation in the Degree Expression 'P Dokoroka Q').” 愛知工業大学研究報告, no. 49 (March): 71-78.

Kennedy, Christopher, and Louise McNally. 2005. "Scale Structure, Degree Modification, and the Semantics of Gradable Predicates." Language 81 (2): $345-81$.

Rusiecki, Jan. 1985. Adjectives and Comparison in English: A Semantic Study. Longman.

Sato, Naoto. 2012. “ドコロカについての一考察 (On Dokoroka 'Let Alone').” 研究 紀要 23: 55-60.

Traugott, Elizabeth C. 1999. "The Rhetoric of Counter-Expectation in Semantic Change: A Study in Subjectification." In Historical Semantics and Cognition, edited by Andreas Blank and Peter Koch, 177-196. Mouton de Gruyter.

Traugott, Elizabeth Closs. 2010. "Revisiting Subjectification and Intersubjectification." In: Kristin Davidse, Lieven Vandelanotte, and Hubert Cuyckens, Eds., Subjectification, Intersubjectification and Grammaticalization, 2970. Berlin: De Gruyter Mouton., 31.

Zhang, Su Fang. 1993. “「どころか」の用法と機能 -「ばかりか」との比較を中 心に- (On the Use and Functions of Dokoroka - Focused on Comparison with Bakarika).” 文芸研究 132: 50-58. 
Index of glosses

ACC accusative

ADV adverbial form

ASP aspectual marker

COMP complementizer

COP copula

DAT dative

GEN genitive

IMP imperative

MOD modality marker

NEG negation

NMLZ nominalizer

NOM nominative

PART particle

PAST past form

PERF perfective form

PROG progressive form

Q interrogative particle

TOP topic particle 